\title{
JACQUES RANCIÈRE E A MODERNIDADE DO MOVIMENTO
}

\section{Jacques Rancière and the modernity of movement}

\author{
Osvaldo Fontes Filho \\ Universidade Federal de São Paulo - UNIFESP
}

Resumo: Este texto expõe alguns momentos da reflexão de Jacques Rancière em torno de uma "contra história da modernidade artística", segundo a qual uma concepção renovada do movimento e da ação dramática teria surgido nos espetáculos de variedades e de dança em fins do século XIX, com reflexos na mecânica das performances no cinema mudo.

Palavras-chave: Modernidade; Movimento; Pantomima/teatro/cinema; Jacques Rancière.

Abstract: This text exposes some moments of Jacques Rancière's reflection on a "counter-history of artistic modernity" by which a renewed conception of body movement and dramatic action would have emerged in the spectacles of varieties and dance in the late nineteenth century, with reflections in the mechanics of performances in silent movies.

Keywords: Modernity; Movement; Pantomime/theater/cinema; Jacques Rancière.

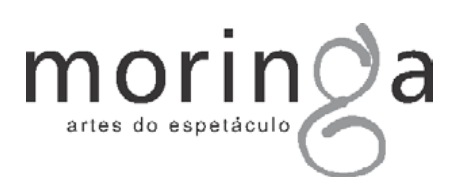


Em 1879, o espetáculo de um grupo de acrobatas ingleses se produzia em Paris, no Théâtre des Folies-Bergère. Palhaços e malabaristas, os cinco irmãos Hanlon-Lees conheceram grande popularidade nos anos 1860-1880. Suas apresentações se distinguiam pela exuberância técnica com que propunham verdadeiras proezas acrobáticas, no limite da possibilidade física. Números de trapézio se alternavam com sketches de pantomima, nos quais cenários elaborados permitiam o aparecer e desaparecer feérico dos corpos, de grande efeito ilusionista. Mallarmé se apercebe que ali, de algum modo, se arruinava a boa ordem das intrigas canônicas e a verborragia do teatro convencional, e mesmo 0 sentido das convenções sociais. Fato é que, ao radicalizar uma assombrosa estética do movimento, os acrobatas ingleses faziam da pantomima uma arte do imprevisível, onde toda posição estável do corpo permanecia ao sabor de sua iminente ruína.

A evocação do nome de Mallarmé, feita na cena $\mathrm{n}-5$ do livro de Rancière, Aisthesis: scènes du régime esthétique de l'art (2011), objetiva deslegitimar a doxa dominante que faz do poeta hermético, à procura por uma linguagem pura, apartado das formas da cultura popular, um dos paradigmas do espírito moderno. Em contrapartida, o trabalho de Rancière, em Aisthesis, de consignação dos momentos em que a Arte moderna encontra seus ritmos e contrarritmos, mostra um Mallarmé convencido de que a linguagem se renovava nas artes do movimento, particularmente nos espetáculos de variedades dos pequenos teatros ou naqueles de dança do music-hall. A figura do poeta seduzido por novas esferas da experiência sensível reforça em Aisthesis uma apreciação do popular que estaria na base de certa modernização da sensibilidade. Diga-se que perfilar protagonistas de um renovado tecido sensível, e dos novos esquemas de sua inteligibilidade, faz parte de uma prosa de retificação em tom de exortação contra esquemas explicativos consagrados - "que não nos enganemos", "cumpre bem compreender", "é preciso bem ver"

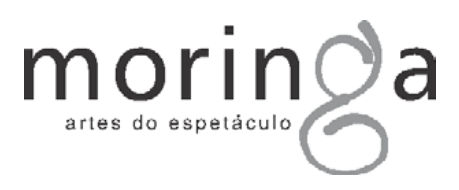


são expressões recorrentes na escrita de Rancière. De fato, a "contra-história da modernidade artística" (2011a, p. 13) a que ele se propõe, por meio de uma ensaística que se recusa a generalizar o que se particulariza nos arquivos, empenha-se em trazer à luz momentos esquecidos, episódios de alguma inflexão cuja memória foi de algum modo reprimida pelas histórias oficiais.

As "cenas" reportadas em Aisthesis não constituem, porém, meros exemplos ou episódios de uma narrativa maior. As novas experiências do popular (do comum, do prosaico), que se estabelecem em um regime estético da arte, com seu modo de equivalência e co-implicação entre as diferentes práticas, não motivam o esforço por uma teoria global. "De um modo geral," testemunha Rancière (2015) "estou mais interessado pelo inventário aberto dos possíveis de um regime do que pela história destinal que o conduz

\footnotetext{
1 Todas as passagens de textos de Jacques Rancière - e de outros autores aqui citados que ainda não possuem edição brasileira estão em tradução minha.
}

a seu fim" ${ }^{2}$. Portanto, referidas a partir de testemunhos diretos, as práticas cênicas comentadas por Rancière não são tanto "obras significativas", por seu hipotético caráter paradigmático, quanto singularidades (de uma performance ou de um comentário) que põem exemplarmente em jogo um medium, ou a partir das quais se alteram as disposições dos corpos, se reconfiguram suas capacidades, aquelas que lhe eram comumente atribuídas, bem como os modos de percebê-las e pensálas. Ainda que atores em espetáculos de entretenimento, os funâmbulos que seduzem Mallarmé não fazem justiça meramente à criatividade inovadora, mas também ao fundo de reflexividade em ato - de tessitura e de retessitura, como aprecia se expressar Rancière - em torno de práticas de expressão que de algum modo mobilizam registros de um renovado meio sensível, de um "novo meio de experiência, um novo mundo técnico que é,

2 Conf. <https://blogs.mediapart.fr/bertranddommergue/blog/310815/entretien-avec-

jacques-ranciere-ou-en-est-lart>. Acesso em 03/11/2018.

Moringa Artes do Espetáculo, João Pessoa, UFPB, v. 10 n. 2, jun-dez/2019, p. 125 a 150

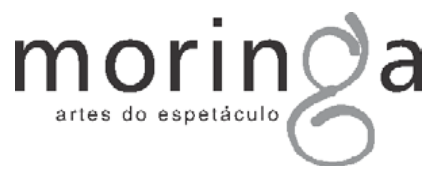


alternadamente, um novo mundo sensível e um novo mundo social" (RANCIÈRE, 2016, p. 33). Ao mesmo tempo em que procuram mostrar um pensamento que se constrói, as "cenas" de Aisthesis põem em causa duas separações comumente reivindicadas pela historiografia ortodoxa: entre as diferentes práticas da Arte, por força da especificidade como dogma de modernidade (ou de modernismo), e entre estas e os discursos que elas motivam. De certo modo, a "cena" faz justiça não tanto ao que se passa diante dos olhos quanto às exigências de uma implicação na trama espectatorial e interpretativa de uma ideia de arte e da realidade sensível a que esta pertence, o que faz do comentário rancieriano um exercício essencialmente parafrástico.

Théodore de Banville, uma das tantas referências textuais de Rancière, também comenta o espetáculo dos artistas ingleses. Poeta e teatrólogo adepto da arte pela arte, cioso de seus hermetismos, Banville não se impede, porém, de emitir um juízo inequívoco: os Hanlon-Lees seriam "os

personagens interessantes que este século produziu", capazes de resgatar seu público "da vil resignação e da platitude universal" que o assoberba. Os palhaços-acrobatas seriam os verdadeiros poetas de seu tempo por permanecerem instintivos em um mundo repleto de lugares-comuns. Eles seriam, ainda, capazes de um pensamento que "plana alado e livre acima das tolices atarefadas" (BANVILLE apud RANCIÈRE, 2011a, p. 101). Por meio de suas evoluções acrobáticas, eles se libertam da gravidade física; por seus gestos exagerados, se furtam às normas sociais; por seu sentido fino do absurdo, anulam as convenções da ação teatral. Pode-se assumir que - juízo aponta para uma arte popular como a forma já existente da arte pela arte: uma arte da performance pura, desembaraçada de qualquer pedagogia moral ou social. Efetivamente, Rancière comenta, os acrobatas ingleses têm a rapidez necessária para transfigurar o rosto humano, o lampejo do olhar que tudo sabe dizer no mutismo, uma agilidade que lhes permite confundir num só movimento desejo e ação, assim

Moringa Artes do Espetáculo, João Pessoa, UFPB, v. 10 n. 2, jun-dez/2019, p. 125 a 150

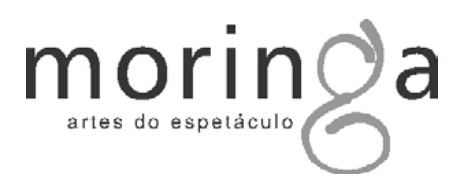


como a energia instintiva mesma do animal, capaz de suprimir, "com a distância do pensamento ao ato, aquela do possível ao impossível" (RANCIÈRE, 2011a, p. 104).

Não há lirismo nesse flerte com o impossível dos movimentos, nessa "idealidade da pantomima", mesmo porque ela é devedora de algumas artimanhas técnicas bastante precisas. $\mathrm{E}$ porque à graça aérea desses corpos de improvável agilidade vêm se contrapor "encontros violentos, entrechoques, quedas: são corpos que escalam alturas e delas degringolam, se esborracham ao solo $e$ se reerguem entre saraivadas de tapas" (RANCIĖRE, 2011a, p. 105). A dualidade entre a graça matreira do palhaço e a agitação violenta do acrobata deixa-se evidentemente explicar como expressão do conflito entre o ideal e a vida empírica. A esse respeito, porém, Rancière retém a observação de Banville: as extravagâncias dos Hanlon-Lees seriam da ordem de um verdadeiro realismo, da vida em sua intensidade devorante e desprovida de sentido. As personagens burlescas que se debatem em cena, esmagadas, esquartejadas, sacudidas como marionetes por uma mão invisível, seriam demonstrativas da vida em sua lógica mesma.

À evidência, os artistas ingleses escapavam do mero registro da ginástica e da proeza circenses para encarnarem uma dramaturgia visual sui generis. Fato é que seus cenários, em constante mutação, permitiam peripécias visuais que prevaleciam sobre 0 encadeamento roteirizado dos acontecimentos. O domínio do movimento, ressaltava um observador da época, Ihes permitia passar da "fixidez [do] tableau vivant [a] uma inenarrável acrobacia, iludindo mesmo a rapidez da visão pela justeza das cambalhotas". Donde a impressão, por parte do espectador, que se era convidado a uma zona indistinta entre sonho e realidade. "Como em um sonho, por força de intensidade e decisão, seus atos são mil vezes mais reais que a realidade, $e$, sobretudo, não admitem nenhuma objeção" (BANVILLE apud MARTINEZ, 2009, p. 163). Aos 
olhos de Mallarmé, os Hanlon-Lees mostravam ser os "reveladores" de uma modernidade assentada nos "raccourcis", nos "lampejos" e na "simplicidade vertiginosa" (MALLARMÉ apud BONNET, 2013, p. 453). Razão porque não restava às demais artes senão se dobrarem a essa nova rítmica do mundo.

Tal histrionismo atlético desses pierrôs-acrobatas dos novos tempos, que não deixavam de ser alegoristas das paixões, "ao levarem ao paroxismo a análise da máscara humana", como sustenta Zola (apud MARTINEZ, 2009, p.164), desautorizava as lógicas causais da verossimilhança e da imitação, os códigos dominantes da conveniência expressiva que desde a época clássica entendia a obra de arte em termos de mímesis. Razão porque Rancière considera a pantomima um antiteatro ou um teatro isento do academismo da tragédia, assim como da grosseria burguesa do melodrama ou da comédia de costumes (RANCIÈRE, 2011a, p. 106). A força da pantomima estaria em sua capacidade de se substituir às palavras para exprimir pensamentos e emoções, de romper com a lógica causal das intrigas e a semiologia da expressão das paixões (RANCIÈRE, 2011a, p. 108). Deslegitimava-se, enfim, a ideia de uma linguagem dos sentidos integralmente motivada. A fórmula da arte popular seria, então, aquela de uma performance sem razão: o personagem popular é o executante virtuose de uma tarefa para a qual permanece indiferente. As palhaçadas dos funâmbulos forneceriam o modelo de uma arte teatral desembaraçada da engenhosidade das intrigas da comédia de costumes. Rancière convoca aqui a apreciação de Théophile Gautier acerca do teatro popular:

tudo [ali] se ata e se desata com admirável desengajamento: os efeitos não têm absolutamente nenhuma causa, e as causas nenhum efeito [...]. Essa confusão e desordem aparentes, no fim das contas, fornecem mais exatamente a vida real sob seus aspectos caprichosos que 0 mais rebuscado dos dramas de costumes. (GAUTIER apud RANCIÈRE, 2011a, p. 110)

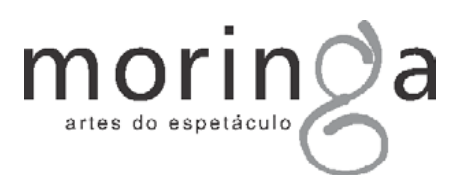


Uma performance cênica, egressa dos meios circenses, desposa as idas e vindas da vida em sua ausência de razão. Com o que contrastar uma arte dramática afeita, desde Aristóteles, aos enredos que entendem imitar as razões da vida por encadeamento de causas e efeitos. Corpos entregues a estímulos implacáveis, à vertigem de rasteiras, socos e tapas, que "fazem a cacofonia de uma artilharia", nos termos de Baudelaire, prestavam-se mesmo a um cômico absoluto, hiperbólico, algo satânico. Um riso que o poeta e dramaturgo Jean Richepin caracterizou como "sem alegria, convulsivo, pleno de espanto". Rancière interpreta-o como a entrada em cena nos divertissements modernos da "civilização nova dos prazeres superexcitados, das doenças nervosas e das visões pessimistas sobre a evolução da humanidade" (RANCIÈRE, 2011a, p. 114). À evidência, os corpos desmantelados dos Hanlon-Lees pertencem a um mostruário capaz de construir, como o pretende Aisthesis, "a história de um regime de arte como aquela de um grande corpo fragmentado e da multiplicidade dos corpos inéditos nascidos dessa fragmentação" (RANCIÈRE, 2011a, p. 14). Drama fulgurante por sua imageria convulsionada, a desorganização performática dos corpos despertou em mais de um espírito a sensação de uma arte absoluta com destino seguro por constituir "simples exibição da doença moderna da alma e da civilização" (RANCIĖRE, 2011a, p. 115).

A dinâmica dos artistasginastas ingleses conheceria seu desdobramento cênico no teatro de Vsevolod Meyerhold, onde o ator deixa de ser o mero intérprete de um personagem para ser instado ao aprendizado de renovada corporeidade pela "aquisição de todos os esquemas gestuais [de biomecânica] que definem uma ação cênica (andar, correr, subir, descer, escorregar, dar cambalhotas ou sapatear, dar um tapa, [...] e assim por diante)" (RANCIĖRE, 2011a, p. 117). A artisticidade estaria em combinar livremente esses esquemas a fim de construir roteiros pantomímicos

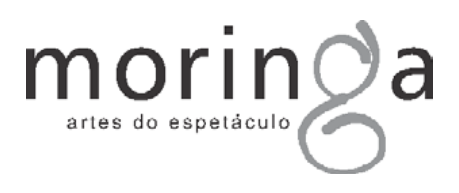


que contrariem as expectativas e aproximem os incompatíveis. O teatro compreendeu que a pantomima seria, pois, o trabalho que permite visualizar o pensamento em performances plásticas no espaço. Assim, Arlequim, Pierrô e Colombina deixavam de ser personagens da tradição que opunham seus gestos tipificados às intrigas dos poderosos. Eles passavam a ser os trabalhadores/ginastas

que desposam os movimentos $\mathrm{e}$ as formas de um novo mundo em construção, como nas cenografias de Meyerhold ou de Lioubov Popova. A mise en scène de Meyerhold para Le Cocu magnifique, de 1922, poderia ser um exemplo apropriado dessa renovada cena teatral. Pois que o cenário futurista lembrava ali os artifícios da trupe circense: escadas oblíquas, passarelas improváveis, platibandas que se encaixavam, rodas e roldanas, uma sucessão de trouvailles espaciais que combinavam, no interior do retângulo cênico, os elementos do universo industrial. Tudo a serviço de um desejo de renovar os modos de ver, de modificar as percepções do espectador. Para além das normativas clássicas do corpo como meio e medium de ação, como funcionalidade presa à lógica da causa e do efeito, surgem novos modos corporais, virtualidades gestuais de certo modo reprimidas pelo domínio continuado de velhas poéticas, presas nas antigas prerrogativas do sujeito em saga. A unidade, a harmonia e 0 direcionamento sensorial do corpo clássico são desafiados por forças vitais profundas e amorfas que fornecem energia a novas disposições, ao mesmo tempo em que debilitam antigas organizações e organicidades.

Em 13 de maio de 1893, Mallarmé assiste ao espetáculo de dança de Loïe Fuller no FoliesBergère. Na cena ํ 6 de Aisthesis, Rancière reporta o parecer do poeta que denota na dançarina americana a expressão de uma "embriaguez feminina" em realização, por assim dizer, "industrial", a serviço de uma arte que flui "incidentalmente, soberana, da vida comunicada a superfícies

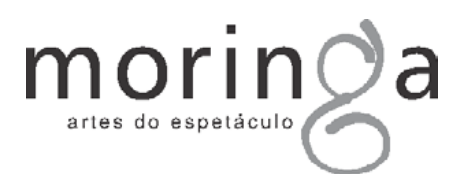


impessoais

"Harmonioso

complementava

(MALLARMÉ apud RANCIÈRE, 2011a, p. 120).

Loïe Fuller tornou-se um ícone do art nouveau ao compor uma dança que não era mais virtuosismo dos pés, nem história coreografada, mas criação de formas no espaço. Ela faz evoluir em torno de si um jogo de véus de crepe e brinca com os efeitos da iridescência produzidos pela iluminação elétrica então nascente. A luz é, de fato, elemento constitutivo do espetáculo: a eletricidade evoca a união entre natureza e artifício, analisa Rancière (2011c, p. 9), meio pelo qual "o espírito se realiza em energia material e a matéria se eleva à condição de potência espiritual". Uma arte inusitada, pois. "Aquela de um corpo novo, aliviado de seu peso de carne, conduzido a um jogo de linhas e tons, turbilhonando no espaço" (RANCIÈRE, 2011a, p. 120). Em Aisthesis, Rancière percorre algumas das estratégias cênicas da dançarina, dos modos como ela se aplica a reconfigurar o conjunto dos elementos do espetáculo: 0 dispositivo da cena, as funções da luz, a arquitetura mesma do lugar. Para tanto, ele recorre às divagações do poeta. Mallarmé sempre evocou a dança como uma "escritura sumária", a única capaz de "traduzir o fugaz e o súbito", elementos constitutivos do "Espetáculo futuro" (MALLARMÉ, 1897 , p. 142). Ele encontrava ali o equivalente do que procurava na poesia: não mais a descrição das coisas, mas o sentir do movimento pelo qual estas se fazem visíveis. De fato, ao suprimir do palco todo elemento de cenário e todo suporte narrativo, Loïe Fuller propunha um espaço não representativo, construído tão somente pelos deslocamentos de seu corpo volteante. Um corpo que é "ponto morto no centro do redemoinho", e que "engendra formas ao se colocar exterior a si mesmo" (RANCIÈRE, 2011a, p. 123). Mallarmé entendeu bem a essência dessa coreografia: o corpo tornavase fusional, a serviço de "nuances velozes", da "rapidez de paixões, delícia, luto, cólera". Para movê- 
las, "prismáticas, com violência ou diluídas, a vertigem de uma alma como suspensa no ar por um artifício" (MALLARMÉ, 1897, p. 179-180).

Esta estética nova, se faz valer os desenhos de uma forma imitada (serpente, borboleta ou flor), não mais se orienta pelo imitativo: os movimentos do corpo dançado restringem-se a ser tão somente rodopios, espirais ou hélices. Loïe Fuller esposava, assim, uma concepção diferente de mímesis, uma "mímesis superior", avalia Rancière (2011a, p. 121), substituindo à história "a construção de um jogo de aspectos, de formas elementares que toma em analogia o jogo do mundo". Para tanto, o corpo recusa a ordem das proporções geométricas: o serpentinado da dançarina é mesmo uma "destruição do orgânico" em favor de uma "linha em variação perpétua”, cujos acidentes se fundem uns nos outros. Com o que suscitar, para aquém das figuras, "uma potência nova do artifício", uma dinâmica ou uma virtualidade genésica, capaz de atravessar os gêneros e as espécies - do modo mesmo como o art nouveau, ondulante e espiralado, terá sido uma arte da comunicação entre as artes, uma arte da tradução e da transformação universais das formas (RANCIÈRE, 2011a, p. 122).

A um tempo figura e fundo, 0 "corpo novo" de Loïe Fuller imitava o aparecer mais que as aparências, o surgir e desenvolver das formas no jogo geral do mundo. Rancière retoma, aqui, uma vez mais, a interpretação de Mallarmé: tratarse-ia de um "corpo que usa de um instrumento material para produzir um meio sensível de emoção que em nada se the assemelha" (RANCIÈRE, 2011a, p. 123). O que faz lembrar como a trajetória da dança moderna inscreve-se numa "história mais ampla da sensibilidade e das emoções" (PERRIN, 2013, p. 52), atenta à condição mesma da existência de um gesto e de sua apreensão pelo espectador. O propósito de Aisthesis é precisamente 0 de desenrolar "o tecido de experiência sensível", "as condições materiais", "os modos de percepção", "os regimes de emoção", "os esquemas de pensamento" que

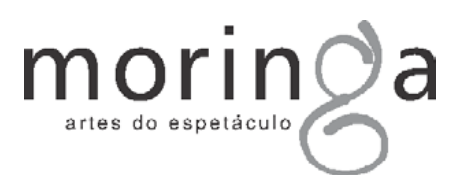


dirigem 0 aparecimento e 0 reconhecimento de um ato artístico (RANCIÈRE, 2011a, p. 10). Razão porque o véu da dançarina aponta para uma "embriaguez de arte" capaz de engendrar formas e emoções em nuanças infinitas. O "corpo não encontrável" da dançarina a que se refere Mallarmé existe apenas como "organizador do jogo das metamorfoses" (RANCIÈRE, 2011a, p. 124). Sua embriaguez não implica preferencialmente nenhuma fúria feminina ou ritual dionisíaco: tratase de um corpo que produz, ele mesmo, o espaço de sua aparição, por mais intermitente que seja. A dançarina do Folies-Bergère "é uma aparição autossuficiente, ela produz por suas evoluções a cena de suas evoluções". Da obscuridade, o corpo dançado surge mesmo como uma descarga elétrica, arrisca-se a interpretar Rancière; o véu que ele faz evoluir em suas dobras e redobras "é a superfície de sua própria aparição que nega a eterna monotonia do 'espaço a si semelhante', rejeita-a em favor do 'nada' da 'atmosfera' assim criada, no vazio"
(RANCIÈRE, 2011a, p. 125). Essa procura pela presença material do espaço pressupõe o esvaziamento cênico de tudo quanto fazia, outrora, o cenário das intrigas dramatizadas. Mallarmé fala de "eclosão contemporânea, milagrosa" de uma "cena livre", aberta ao atmosférico das paixões (MALLARMÉ, 1897, p. 181).

Ainda que involuntariamente, Loïe Fuller prenuncia o espaço abstrato que o teatro de Adolphe Appia, dentre outros, materializaria em breve para uma dramaturgia desimpedida das personificações e intrigas da tradição teatral. Privilegiar o aparecer mais que a aparência implica em operação de supressão da distância entre a vontade e sua realização, entre 0 artista e a obra, entre a obra e o espaço onde se produz. Razão porque a dançarina dos véus incorpora renovada performance, na qual o corpo em movimento não mais necessita de um texto a partir do qual exercite sua arte de convencimento cênico. Ela marca mesmo precisa operação de autonomia, de supressão da intencionalidade do artista. $\mathrm{O}$ corpo

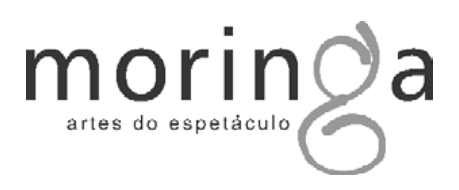


de Loïe Fuller permanece "imóvel", já o notara Mallarmé, no centro dos redemoinhos engendrados por seus véus. Nesse particular, ela rompe com a lógica clássica do corpo articulado em torno da sucessão dos acontecimentos, em torno de uma linha narrativa com começo, meio e fim. "O corpo se abstrai de si mesmo, ele dissimula sua própria forma no desdobramento dos véus, desenhando o voo mais que o pássaro, o turbilhonamento mais que a onda, a desabrochar mais que a flor" (RANCIÈRE, 2011a, p. 127). O que é imitado de cada coisa, complementa Rancière, é o acontecimento de sua própria aparição.

Ser moderno, à vista dos exemplos evocados em Aisthesis, terá consistido em se demover de algumas correspondências regradas entre a expressão e as emoções e juízos que esta era constrita a ilustrar ou suscitar em um regime representativo das artes (RANCIÈRE, 2011c, p. 1). Aisthesis se compromete, pois, a traçar itinerários possíveis no que Rancière chama de a história do regime estético da arte, dos momentos em que a lógica da Arte (no singular, como modo específico de ser e habitar no sensível) se constrói na ruína de critérios de distinção, inclui territórios inéditos e forja, para tanto, novas disposições da sensibilidade (RANCIÈRE, 2011a, p. 12). Essa lógica refere uma crítica da representação em formas artísticas como a mise en scène, a dança, a pantomima ou mesmo as artes decorativas, todas tomadas como momentos de uma grande metamorfose, de um processo de devir-vida da arte, que se de um lado se autonomiza, de outro se identifica com o ordinário das práticas da vida coletiva. Os artistas circenses e a dançarina do music-hall são, cada qual à sua maneira, modos de aceder a uma arte por assim dizer "aplicada", uma arte que "habita e exprime" a vida preparada pela ideia de arte pura e suas reivindicações espirituais (RANCIÈRE, 2011a, p. 181-183). O que remete, ainda, ao duplo registro do regime estético da arte: das metamorfoses e reconfigurações das partilhas do

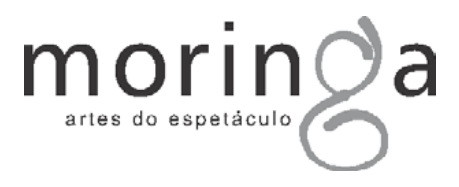


sensível, mas também da fragmentação, mistura e confusão das artes, da abolição das hierarquias artísticas, portanto da ruptura com as normativas do regime representativo.

Corpos fragmentados, em perda de organicidade, exprimem literalmente uma decapitação da comunicação por muito tempo centrada nos valores da cabeça. Vários capítulos em Aisthesis, inspirados pelas performances teatrais e pelos espetáculos de divertissement, colocam esse ponto em destaque. Antiteatral, a pantomima não representa uma ação disponível na forma de linguagem ou texto: ela prescinde da trama, da narrativa ou das sequências da razão; não substitui a palavra, mas a desautoriza, ou a ridiculariza - como numa gargalhada ou num insensato impulso do corpo. Acéfalo, o palhaço não pretende dizer ou significar algo, donde o caráter "satânico", observado por Baudelaire, do riso causado por sua anarquia primária. Os ginastas Hanlon-Lees, ou mesmo os véus em convulsão de Loïe Fuller, liberam movimentos que não levam a lugar algum, movendo-se na plena imanência, sem sobrevoo simbólico ou texto a ilustrar, sem a sombra de uma ideia a defender, mas colocando em plena luz, especialmente graças ao reforço da mecânica e da eletricidade, um caos de formas em perpétua mutação. A esse respeito pode-se falar, como o faz Rancière (2011a, p. 133), de um espaço de indistinção, com a consequente negação das supostas especificidades das matérias e dos procedimentos expressivos. O meio sensível que então se articula apresenta-se como aquele de um desdobramento de potências e formas - "gestos de mundo, esquemas de mundo" - anteriores a toda normativa ligada a alguma particular disciplina artística.

Não por acaso, o art nouveau nutre o ideal de uma natureza materializada em formas simplificadas, como potências produtivas que se confundem com sua processualidade. Cruzam-se, assim, na mesma idealidade de movimento, o traçado gráfico de um poema, as rítmicas de um

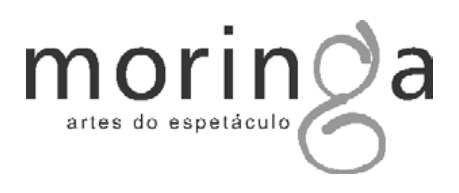


diálogo ou de uma superfície, os volteios de uma estatueta, os floreados de um móvel; enfim, toda iridescência de formas e corpos que, para além da mera função analógica, adquirem potencial de reverberação, ainda que efêmero, em suas manifestações artísticas. A perspectiva é demonstrativa da denegação de todo esquema explicativo da arte moderna que reúna, em uma mesma fórmula, autonomia e especificidade. Importa, aqui, reter in extenso a leitura rancieriana:

A arte autônoma que então é sonhada, entre a página de escrita, a partição sinfônica, o teatro de sombras, a pantomima ou a dança luminosa, mas também entre a mistura óptica das cores, a vibração da pincelada ou o espaço enclausurado do quadro, aquela que em breve será sonhada entre a mise en scène, a fotografia ou 0 cinema, não é aquela cuja posteridade fixará a doutrina a obra resistente, bem instalada na exibição de sua materialidade. É outra coisa: a arte que nega toda especificidade de matéria e se identifica com

desdobramento de um ato puro, inteiramente material em um sentido, pois que consiste em montagem de formas corporais sustentada por tudo quanto a técnica pode inventar; mas também inteiramente espiritual, porque ela não quer reter dos corpos mais que sua potência de criação de um meio sensível, e porque ela existe apenas no tempo de uma manifestação voltada a seu próprio desaparecimento.

(RANCIÈRE, 2011a, p. 136)

Não é, pois, casual que Rancière perceba, nessa forma espiritual da matéria, que equivale a uma forma material da espiritualidade, os sinais inequívocos de uma embriaguez formal que em breve repercutiria em sua plena realização industrial. Razão porque ele identifica nos engenheiros-artistas da Bauhaus ou nos construtivistas russos os agentes de uma vocação moderna da arte, "aquela de uma perda de hierarquia e de especificidade que reservava aos artistas a tarefa de construção das formas e do mobiliário da nova vida" (RANCIÈRE, 2015³).

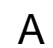

\footnotetext{
${ }^{3}$ Conf : $\quad<$ https://blogs.mediapart.fr/bertranddommergue/blog/310815/entretien-avec-

jacques-ranciere-ou-en-est-lart>. Acesso em: 03 nov. 2018.
} 
modernidade traça, assim, percurso que difere do que dela trata certa vulgata em torno da noção de "modernismo".

Caberia aqui alguma ressalva. Ainda que se possa alinhar com a cisão interna de um discurso que não mais se pretende contínuo ("É outra coisa"), não estaria Rancière, nas escolhas que faz em Aisthesis, nas cenas que convoca, dando involuntariamente razão a Hal Foster (2013) em sua reticência quanto aos "filósofos da estética" que, segundo ele, tenderiam a se fixar em um momento ou em um modelo de prática artística a fim de "ontologizá-los como arte", e então usar esse dado reificado para seus próprios esquemas conceituais? A reticência, que visa diretamente a noção de "regime estético" em Rancière, poderia mesmo se estender ao título proposto para o presente texto. Haveria, de fato, porque falar de uma "modernidade do movimento"? Mas, o que de fato entender por "modernidade", pois que Aisthesis, um texto implicado na "mutação das formas de experiência sensível e das maneiras de perceber e de ser afetado" (RANCIĖRE, 2011a, p. 9), parece deslocar as linhas de interpretação usuais? Relembre-se, aqui, as reticências do próprio Rancière ao conceito de "modernidade". Basicamente, o regime estético das artes não teria começado com decisões de ruptura artística; as revoluções estéticas das vanguardas não se caracterizariam por reinventar sem interrupção o novo. Na verdade, o regime estético seria movido por "decisões de reinterpretação daquilo que a arte faz ou daquilo que a faz ser arte" (RANCIÈRE, 2009, p. 36). Estético é, antes de tudo, um regime de encenação incessante do passado, e um modo de constituir como o princípio mesmo da artisticidade uma relação de expressão de um tempo e de um estado de civilização que, antes, era a parte assumida "não artística". Assim, quando futuristas ou construtivistas proclamam o fim da arte e a identificação de suas práticas com aqueles que constroem, pontuam ou mobíliam os espaços e tempos da vida comum, eles propõem a arte como

Moringa Artes do Espetáculo, João Pessoa, UFPB, v. 10 n. 2, jun-dez/2019, p. 125 a 150

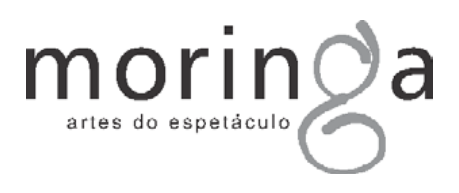


uma identificação com "modos de discurso, formas de vida, ideias do pensamento e figuras da comunidade", bem como com "as formas pelas quais a vida se forma a si mesma" (RANCIÈRE, 2009, p. 14 e 34, respectivamente). Do mesmo modo, Rancière identifica nos espetáculos do Folies-Bergère compromissos com os espaços e tempos que então começavam a ritmar e ocupar a vida em comum. "Modernidade" seria, pois, um termo equivocado se entendesse conotar tão somente gestos de ruptura, separando-os do contexto geral, interno e externo às artes, que os autoriza. A "autonomia" de que trata 0 modernismo não se reduz a uma recusa do figurativo. Aisthesis mostra como as formas do espetáculo popular, dos HanlonLees a Charlie Chaplin, passando pela dança "elétrica" de Loïe Fuller, ajudaram a construir a modernidade bem mais que qualquer realização que porventura corrobore a ideia de um "destino global antimimético da 'modernidade' artística" (RANCIÈRE, 2009, p. 35). Estas manifestações nos falam mais, hoje, que qualquer manifesto modernista. Seríamos modernos por força de outros esquemas que as fórmulas rebarbativas que multiplicam as mesmas referências a Dada, Duchamp ou Malevitch. Nem a "Fonte", nem o "Quadrado Negro sobre Fundo Branco", lugares incontornáveis das vanguardas históricas, aparecem merecedores de atenção por parte de uma autodenominada "contrahistória da modernidade". Se a noção de "modernidade" é contrafeita em sua historicidade canônica, tal se deve ao fato de Rancière a pensar fora das explicações em torno do modernismo e seus postulados de desenvolvimento formal e de destino histórico - o "próprio da arte" e uma "teleologia simples da evolução e da ruptura históricas". As teses do modernismo deveriam, ao contrário, ser entendidas a partir da promoção em esfera artística de uma equivalência sensível - das "passagens e misturas que arruinavam a ortodoxia da separação das artes" (RANCIĖRE, 2009, p. 41) - em oposição às hierarquias de gênero, princípios de verossimilhança e critérios de

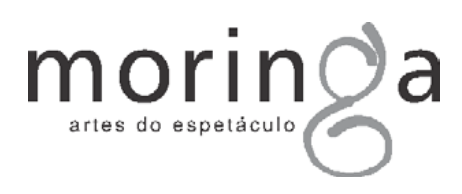


distinção do sistema da representação.

Ressalvas à parte, fato é que Aisthesis considera a revolução estética como uma "interminável ruptura com o modelo hierárquico do corpo, da história e da ação" (RANCIÈRE, 2011a, p. 15). Interminável, pois que ressurgências hierárquicas permanecem sempre possíveis, assim como as rupturas podem advir como desvios, contrapontos por vezes paradoxais. Não por acaso essa é uma história construída a partir de uma cena inicial, na qual Winckelmann, autor a partir do qual "a Arte começa a se dizer como tal" (RANCIĖRE, 2011a, p. 13), propõe uma leitura inesperada de um torso fragmentado da Antiguidade. Neste se deslegitimariam os dois grandes critérios em uso na ordem representativa: "primeiramente, a harmonia das proporções, ou seja, a congruência entre as partes e o todo; em seguida, a expressividade" (RANCIĖRE, 2011a, p. 22). Há, pois, essa primeira trama em Aisthesis que convoca um corpo desmembrado e decapitado para falar de neutralização da expressividade, de equivocidade da forma e de suspensão da narração. Winckelmann propõe como modelo um corpo que renuncia à proporção orgânica e à expressão do rosto, um corpo em transição da ação voluntária aos movimentos autônomos da vida (RANCIÈRE, 2011c, p. 8). Enfim, um corpo indiferente, impassível, inexpressivo ou imóvel (muito diferente do corpo do guerreiro ativo, ideal de perfeição da vida coletiva antiga), que se torna o receptáculo paradoxal de movimentos e forças que quebram as ilusões da intencionalidade de exceção.

$\mathrm{Na}$ recusa do motus contínuo da "lógica da autoridade", - comentário rancieriano se oferece, por fragmentos, como um desvio da função crítica da explicação. A descrição em Winckelmann fornece, de imediato, o mote; ela que celebra, junto ao torso de Hércules, a virtude de um "escoamento incessante de uma forma em outra" (RANCIĖRE, 2011a, p. 19). Esse movimento - 
que não permite ignorar que toda realidade ideal encontra sua verdade em imperativos materiais bastante prosaicos - se constitui em clara oposição às antigas idealidades da história e da ação (RANCIÈRE, 2011c, p. 4). $\mathrm{Na}$ observância de tal mutação de categorias, Rancière vê surgir, aqui e acolá, uma plástica elaborada a contrário do princípio clássico "que obrigava o corpo a exprimir um sentimento determinado ou um momento determinado de uma ação significativa" (RANCIĖRE, 2011a, p. 190). Corpos inacabados ou dispersos em uma proliferação monstruosa de suas partes (como nas estátuas de Balzac e Victor Hugo, ou nas Portas do Inferno, de Rodin) exprimem a dinâmica que uma estética niilista sugere, qual seja, os movimentos anárquicos de uma Vida que é "potência infinita de invenção de formas totalmente imanentes aos movimentos e encontros dos corpos" (RANCIĖRE, 2011a, p. 194-195 e 198). Na vida moderna, essa potência investe a multiplicidade dos gestos, muitos despercebidos ou à procura de seu próprio sentido, pois que não governados pela "linha reta do ponto de partida ao ponto de chegada" (RANCIÈRE, 2011a, p. 199).

Uma Arte atenta à potência própria das coisas ou das frases, aos movimentos desregrados da Vida, encontra no cinema um meio de reapropriação dos tantos experimentos cênicos (materialidades, usos do espaço/ tempo e do corpo cenografado) maturados nos pequenos teatros do entretenimento popular. Junto com a fotografia, o cinema é a arte de um novo mundo sensível regido pela luz e pelo movimento: um mundo afeito às intensidades $\mathrm{e}$ velocidades, "onde a matéria se espiritualiza em energia luminosa e motriz e onde o pensamento e o sonho têm a mesma consistência que a matéria instrumentalizada" (RANCIÈRE, 2016, p. 34). Rancière ressalta, ainda, que 0 cinema nasce em tempos de grande suspeita quanto às histórias, quando uma arte nova não mais descrevia o espetáculo das coisas, não mais apresentava os estados de alma de

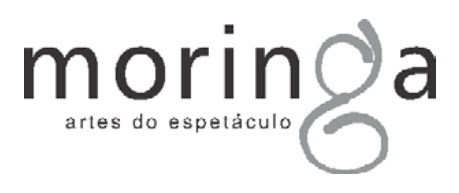


personagens, mas "inscrevia diretamente 0 produto do pensamento no movimento das formas" (RANCIĖRE, 2011b, p. 16). Nesse sentido, o cinema parece ter desempenhado um

papel expressivo nas reconsiderações em torno da modernidade em arte. Em As distâncias do cinema, Rancière assinala: "a história da pureza modernista vencida pelo qualquer coisa pós-moderno esquece que a diluição das fronteiras ocorreu de maneira mais complexa em outros lugares como o cinema" (RANCIÈRE, 2011b, p. 9). A investigação dessa diluição se sistematiza em Aisthesis, com foco na circulação entre as artes, mas igualmente entre a arte e a vida. Afinal, o movimento próprio ao regime estético, aquele que sustentou os sonhos de novidade artística e de fusão entre a arte e a vida sob a bandeira da modernidade, "tende a apagar as especificidades das artes e diluir as fronteiras que as separam entre si como as separam da experiência cotidiana" (RANCIÈRE, 2011a, p. 13).
O potencial do cinema então nascente residia na aliança que possibilitava entre o mecânico e o humano, em sua capacidade de modificar as velocidades, de fragmentar as ações, de desviar as trajetórias, portanto, de incorporar aquela "potência espacial de ilusão" de que falava Mallarmé. Ele assim substituía a ciência das intrigas, a representação das personagens e a encarnação dos sentimentos pela imediatez das figuras mudas, "que fazem efeito ao se fundirem no desenho de um contorno ou ao se singularizarem por alguns gestos e atitudes rudimentares" (RANCIÈRE, 2011a, p. 234). De certo modo, o cinema punha em cena, espetacularmente, uma nova redistribuição da relação entre o "qualquer um" e o todo; em outros termos, ele contribuía para a reconfiguração de um pensamento do comum, no qual tanto insiste 0 pensamento de Rancière. Consequentemente, a Arte tendia ali a se demonstrar cabalmente, como o efeito de uma perturbação das relações entre noções comumente antitéticas: movimento e ação, pensamento e ação, 
trabalho e diversão, arte e mecanicidade, exemplar e comum, organismo e vida, performance popular e coreografia formal, dentre outras.

Nesse particular, a obra de Charles Chaplin representa expressiva reapropriação de modos cênicos. Carlitos é um personagem que não interpreta: ele reage. Trata-se de um ser movido por estímulos, situação que perverte a lógica do sujeito, aquela que sempre sustentou a arte do ator, com seus predicados ordinários (autonomia, reflexão, responsabilidade, etc.). Protagonista às voltas com mecanismos da vida cotidiana que frustram sua vontade, suas iniciativas ilustram uma funcionalidade paradoxal que não cessa de flertar com seu contrário. Razão porque a figura de Carlitos se inscreve, sem dificuldades, numa reflexão sobre a ação e o movimento que passa pela inércia paradoxal de Julien Sorel, pelo drama sem ação de Maeterlinck, ou pelos heróis pouco heroicos de Ibsen.

Importa lembrar aqui como, em Aisthesis, Rancière se mostra interessado nas "mudanças de olhar"; suas cenas são mesmo assumidas como "máquinas ópticas", instadas a (de)monstrar mudanças na sensibilidade do espaço e do tempo. A cena rancieriana não é mera ilustração de uma ideia. Ela é, antes, uma "máquina ótica que nos mostra 0 pensamento ocupado em tecer laços que unem percepções, afetos, nomes e ideias, em constituir a comunidade sensível que esses laços tecem e a comunidade intelectual que torna esse tecido pensável" (RANCIÈRE, 2011a, p. 12). O que importa é saber, a cada feita, como algo se torna pensável, e não o que é preciso pensar por força desta ou daquela explicação. Enfim, o que importa é saber "como uma dançarina que agita véus ou um mímico acrobata se tornam paradigmas da grande arte, como é possível que Chaplin, uma espécie de palhaço, se torne o paradigma da arte moderna" (RANCIĖRE, 2011c, p. 5). Por tudo quanto se mostrou acima, a passagem soa um tanto paradoxal. Seja como for, tem-se a impressão que Rancière procura em Carlitos uma

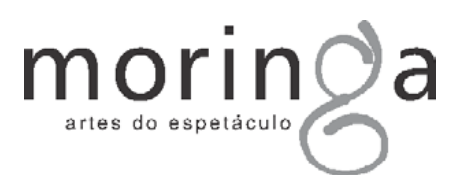


ressonância do impessoal no individual que tanta presença fornece aos objetos e gestos banais captados pela fotografia; ou, então, aquela expressão da Vida no banal que tanto aprecia no drama sem ação (da vida ordinária) de Maurice Maeterlinck; ou, ainda, aquele "corpo dançante" que não mais adapta sua mímica ao caráter do personagem que encarna, mas que traduz diretamente a vida infusa na condição que vivencia, como prescrevia a mise en scène de Adolphe Appia para os dramas de Ibsen (RANCIÈRE, 2011a, p. 153).

Fato é que o gestual do vagabundo recusa todo sentimentalismo de fácil recepção em favor de uma mutação quase que instantânea dos estados de espírito: os ombros caídos do derrotado pela vida podem prontamente se reerguer para desferir algum golpe que the mude a sorte; os olhos acabrunhados podem revirar em olhar predador à vista de alguma oportunidade de furto ou recompensa fácil. Todo um gestual que se presta ao equívoco e que, portanto, se opõe aos códigos expressivos; uma mímica que deslegitima toda verborragia edificante (RANCIÈRE, 2011a, p. 237). Uma mecânica corporal garante, assim, seu êxito cênico pela total imprevisibilidade de seus efeitos. Eis o que transforma os movimentos exatos do mímico popular em puras formas plásticas inscritas na tela. De algum modo, o corpo desimpedido das deliberações do pensamento e dos sentimentos inequívocos pode se dar a um "puro traçado gráfico repudiando toda gravidade corporal" (RANCIÈRE, 2011a, p. 235).

Os volteios e equilíbrios instáveis do "palhaço biomecânico" se fazem com os elementos mesmos do trabalho ou da banalidade cotidiana. A precisão mecânica do movimento, ainda que no registro do vulgar paródico, trai a intenção de emular o ritmo da máquina. Não que se vise à mera crítica da mecanização dos modos e meios. A síntese da pura forma visual e da gestualidade carnavalesca, que está igualmente no teatro de Meyerhold, esclarece, antes, um modo renovado de

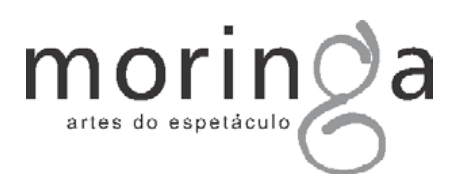


entender a arte do ator. Doravante, afeito à economia dos modos de expressão, à precisão dos movimentos, 0 ator se identifica com "o engenheiro de sua própria mecânica” (RANCIÈRE, 2011a, p. 239). Tal obsessão pela mecânica do corpo expressivo faz do pequeno vagabundo paradigma, no cinema de massas nascente, de uma antidramaturgia própria a figurar particular (e paradoxal) eficácia da ação moderna na era das máquinas. O homenzinho de bengala e chapéu coco não é tanto um sentimental quanto "um biomecânico mascarado sob os trajes de um bastardo de comédia". Sua gestualidade, de um virtuose da falta de jeito e do malogro, faz dele um habitante exemplar de um novo universo sensível, aquele das máquinas que realizam e negam ao mesmo tempo a vontade e seus fins, e que impõem "a repetição teimosa de um movimento cuja perfeição própria é a de não querer nada por si mesmo" (RANCIĖRE, 2011a, p. 241).

Portanto, o cinema coloca em pauta a figura sui generis de uma inércia em perpétuo movimento, apreendida tanto na imediata eficácia da reação quanto na vacuidade de uma mecânica que retoma sempre sua posição inicial. Rancière vê nisso algo já presente em Winckelmann e em Hegel: a modernidade que se figura numa paradoxal indistinção entre excesso e falta, movimento e repouso. Ele ousa mesmo redefinila a partir de momentos de indeterminação que dinamizariam a história da arte: moderna teria sido uma época na qual os artistas se empenharam em "desencadear as potências sensíveis ocultas na inexpressividade, na indiferença ou na imobilidade", bem como em "compor os movimentos contrariados dos corpos dançantes, da frase, do plano ou da pincelada colorida que detêm a história ao contá-la, suspendem o sentido ao transmiti-lo ou sustam a figura mesma que designam" (RANCIÈRE, 2011a, p. 28). regime estético da arte revela que a modernidade da vontade está ligada a seu esgotamento em face da "marcha teimosa de uma vida que nada quer". Razão para ir ter com movimentos liberados pela dissociação entre forma, função e expressão, submetidos doravante

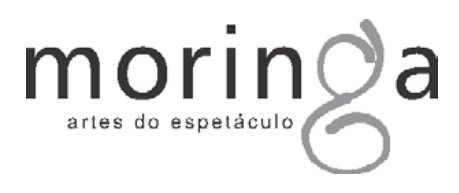


ao crivo das luzes do cinematógrafo.

Carlitos personifica-os exemplarmente: antipersonagem dotado de uma inércia constantemente contrariada, ele é o sujeito "sobre o qual os acontecimentos recaem ininterruptamente, para fora de toda lógica causal tradicional" (RANCIĖRE, 2011c, p. 3). Com ele, conclui Rancière (2011a, p. 242), o cinema "metaforiza uma maneira singular de habitar o mundo novo das grandes empresas da vontade e das performances da máquina". Em "Tempos Modernos", o artista dança o balé do homem moderno, no ritmo compassado de uma mecânica repetitiva. Mas, o que de fato demonstra o mímico cinematográfico, para além da evidente identificação da mecânica da montagem e da "vontade planificadora do novo mundo maquínico" (RANCIĖRE, 2011a, p. 243), é o que já estava implícito nas peripécias circenses dos Hanlon-Lees e nos volteios luminosos de Loïe Fuller: o frenesi da pantomima ou da coreografia torna inseparáveis a precisão maquínica e as ilusões do desvario, a astúcia infalível e o fracasso certo, a teimosia obstinada e o abandono ao acaso. Por obra do cinema, a arte se vê "própria a exprimir o niilismo secreto que acompanha a grande fé maquínica" (RANCIÈRE, 2011a, p. 206). Com que revisar os modos correntes de entendimento da modernidade. Como sublinha o comentador: "agir sem plano, agir sem nada querer, abster-se de agir, expressar para não significar ou nada pretender: essas figuras paradoxais de ser (um corpo) no mundo constituem para Rancière a camada mais profunda da experiência moderna" (DERANTY, 2013). Este é o ponto nulo em que o sentido e o sem sentido se fundem, indistinguíveis; este é o nó central na trama mesma do regime estético a que tantos filósofos e escritores modernos têm sido sensíveis.

Recebido em 16/01/2019

Aceito em 08/03/2019

\section{Referências Bibliográficas}

BONNET, Gilles. La pantomime fin de siècle, caprice moderne. In:

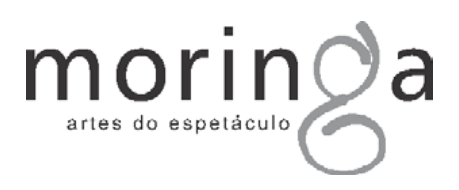


VAILLANT, Alain e DE VILLENEUVE, Roselyne. Le rire moderne. Paris: Presses universitaires de Paris Nanterre, 2013, pp. 453-466. Disponível em: $<$ https://books.openedition.org/pupo /3676>. Acesso em: 01 nov. 2018.

DERANTY, Jean-Philippe. The Symbolic and the material: a review of Jacques Rancière's Aisthesis: scenes from the aesthetic regime of art. Parrhesia, $\mathrm{n}^{\circ}$ 18, 2013, pp. 139-144. Disponível em: <https://www.parrhesiajournal.org/p arrhesia18/parrhesia18_deranty.pdf >. Acesso em: 12 nov. 2018.

FOSTER, Hal. What's the problem with critical art? London review of books, no 19, 10 outubro, 2013. Disponível em: <https://www.Irb.co.uk/v35/n19/halfoster/whats-the-problem-withcritical-art>. Acesso em: 05 nov. 2018.

MALLARMÉ, Stéphane. Divagations, 1897. Disponível em: $<$ https://fr.wikisource.org/wiki/Divag ations_(1897)/Texte_entier>. Acesso em: 01 nov. 2018.

MARTINEZ, Ariane. Défense et illustration du théâtre d'images à travers quelques allers-retours entre le XIXème siècle et aujourd'hui. L'Annuaire théâtral,
(46), 2009, pp. 159-168. Disponível em:

$<$ https://www.erudit.org/fr/revues/an nuaire/2009-n46-

annuaire3980/045377ar/>. Acesso em: 02 nov. 2018.

PERRIN, Julie. Ler Rancière a partir do campo da dança contemporânea. AISTHE, Vol. VII, no 11, 2013, pp. 42-60.

RANCIÈRE, Jacques. Aisthesis: Scènes du régime esthétique de l'art. Paris: Galilée, 2011a.

RANCIÈRE, Jacques. Entretien à Eric Loret. Libération, 2011c. Disponível em: $<$ http://www.editions-

galilee.fr/images/3/p_97827186085 25.pdf>. Acesso em: 10 nov. 2018.

RANCIÈRE, Jacques. Entretien avec Jacques Rancière, par Bertrand Dommergue: Où en est l'art? Mediapart, 31 agosto 2015. Disponível em: $<$ https://blogs.mediapart.fr/bertranddommergue/blog/310815/entretienavec-jacques-ranciere-ou-en-estlart>. Acesso em: 03 nov. 2018.

RANCIÈRE, Jacques. Les Écarts du cinéma. Paris: La Fabrique éditions, $2011 \mathrm{~b}$.

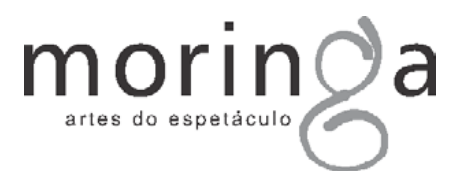


RANCIÈRE, Jacques. A partilha do sensível. Estética e política. Trad. Mônica Costa Netto. São Paulo: Ed. 34, 2009.

RANCIÈRE, Jacques. O que "médium" pode querer dizer: o exemplo da fotografia. Trad. Pedro Lapa. Medium/Post-Medium oscillations in contemporary art, no $\quad$ 4, 2016. Disponível em:<http://artison.letras.ulisboa.pt/i ndex.php/ao/article/view/101/94>.

Acesso em: 05 nov. 2018.

RANCIÈRE, Jacques. A modernidade revisitada, 2012. Disponível em: $<$ https://gestaoculturalesad.files.wor dpress.com/2012/10/amodernidade-revisitada.pdf>. Acesso em: 08 nov. 2018. 
Moringa Artes do Espetáculo, João Pessoa, UFPB, v. 10 n. 2, jun-dez/2019, p. 125 a 150

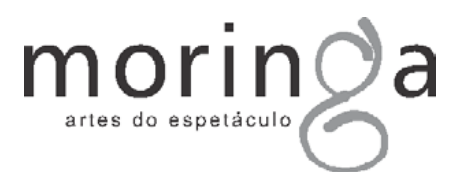

